\title{
EL REALISMO "FULL HD" DE JUAN FRANCISCO FERRÉ
}

\author{
AmÉLIE FLoRENCHIE \\ Université Michel de Montaigne - Bordeaux 3
}

Juan Francisco Ferré nació en Málaga en 1962. Es escritor y crítico de cine ${ }^{1}$ y literatura ${ }^{2}$, autor de varias obras ${ }^{3}$, entre la cuales destaca la novela Providence (Anagrama, 2009) sobre la que se va a concentrar nuestro estudio. Se le suele relacionar con un grupo de escritores denominados los Nocilla (o también los Mutantes), creado en 2007 a raíz de la publicación de la novela Nocilla Dream por Agustín Fernández Mallo. Las etiquetas "nocilla" y "mutante" merecen quizás un breve análisis: la nocilla, además de ser "una mezcla de leche cacao, avellanas y azúcar", como dice el anuncio, también es un símbolo de la sociedad de consumo que emergió en España a principios de los años 70 para toda una generación de jóvenes que se crió con la televisión. Del mismo modo, "mutante" remite a la voluntad de cambio de esta generación y a su aspiración por "reventar la tradición",

\footnotetext{
${ }^{1}$ Juan Francisco Ferré tiene un blog titulado La vuelta al mundo (<http://juanfranciscoferre.blogspot.fr/>).

${ }^{2}$ Doctor en filología hispánica, defendió una tesis sobre la obra de Juan Goytisolo; también fue profesor de Literatura y Cine Español e Hispanoamericano en la Universidad de Brown en EEUU de 2005 a 2011, una experiencia en la que se inspira en gran parte su última novela Providence.

${ }^{3}$ Es también autor de las novelas La vuelta al mundo (Jamais, 2002), La fiesta del asno (DVD ediciones, 2005) -prologada por Juan Goytisolo-, Karnaval (Anagrama, 2012) -ganadora del Premio Herralde-, de una recopilación de cuentos titulada Metamorfosis $\AA$ (Berenice, 2006), del ensayo Mímesis y simulacro. Ensayos sobre la realidad (Del Marqués de Sade a David Foster Wallace) (e.d.a. libros, 2011), y del catálogo de la instalación de Pablo Alonso Herráiz I love you Sade (e.d.a., 2003). También coeditó con Julio Ortega una antología de autores de la nueva generación, titulada Mutantes (Berenice, 2007).
} 
según la expresión de Vicente Luis Mora (Azancot 2007). Así mismo se trata de una referencia a la "mutación" que han provocado desde los años 90 las nuevas tecnologías de la información y comunicación en nuestras sociedades, y, en particular, en el sistema cultural y el desarrollo de la cultura de masas. Entrevistado por Nuria Azancot en 2007, Mario Cuenca Sandoval, uno de los miembros del grupo, destaca

\begin{abstract}
... además de esa incorporación del mundo de los medios de masas como tejido narrativo autónomo, la disolución de la frontera entre alta cultura y cultura popular. Ponemos en pie de igualdad el mundo del cómic y el de la música culta, por ejemplo. Los mitos que incorporamos son tanto los del mundo clásico como los del cine de zombis. La idea de que hay un centro y una periferia de la cultura parece disuelta por la práctica narrativa de, por ejemplo, Fernández Mallo o Mora. No responde, creo, a un propósito, sino a una forma de mirar. (Azancot 2007)
\end{abstract}

Un grupo que se define por su doble adscripción cultural: académica y de masas, y, por lo tanto, por el dominio de las nuevas tecnologías de la información y la comunicación que la sustentan, situándose más allá -temporalmente- de la posmodernidad definida por Jameson (1991: 35), en una corriente estética conocida como el "afterpop", según Eloy Fernández Porta (2010: 21). Sus paradigmas estéticos son el remix o el sampling, ambos términos de origen musical, que remiten a la idea de mezcla y abolición de las fronteras culturales. Juan Francisco Ferré forma parte de este grupo de escritores que reivindica la hibridez absoluta de su cultura: en su caso una cultura literaria que sugiere la pasión por la mezcla -influencias de Goytisolo pero también de escritores norteamericanos que reinventan sin cesar los paradigmas de la cultura norteamericana, bajo la influencia de los cultural studies, como Thomas Pynchon o David Foster Wallace ${ }^{4}-$. Una cultura académica -referencias a Nietzsche en La fiesta del asno por ejemplo-, pero también, una cultura de masas o subculture, a través del cine-de los Blockbusters al cine independiente, pasando por el cine de bajo presupuesto, y en particular pornográfico (muy presente en Providence)-, o del vídeo, de la producción televisiva -desde los anuncios hasta las teleseries, pasando por los dibujos animados, la telerrealidad y los videoclips-, de la música pop -referencias a James Blunt, Britney Spears, etc.- y del videojuego, que ocupa el centro de mi reflexión. De esa hibridación hasta se hace eco la portada de Providence: se trata de la versión popart a lo Warhol de un retrato del escritor H. P. Lovecraft, creador de un universo original, recuperado por la ciencia ficción y la estética underground, nacido en Providence en 1890 y en cuya tumba aparece el epitafio siguiente: "I am Providence". Como escribe Juan Goytisolo a propósito de Providence:

Atento lector de Cervantes, Juan Francisco Ferré compendia en Providence las manifestaciones artísticas contemporáneas -el cine, la tele, la omnívora Red,

\footnotetext{
${ }^{4}$ Es también notable la influencia de escritores norteamericanos como Mark Danielewski (Providence le debe mucho a The house of leaves), J. G. Ballard (véase por ejemplo Crash), Philip K. Dick, William Gibson, Robert Coover, William Bourroughs, Breat Easton Ellis o Don Delillo.
} 
los mitos y falacias de la utopía cultural norteamericana- para machacarlas y mezclarlas en su batidora. Las figuras icónicas del pop art y el hip-hop, los blogueros apocalípticos y visionarios ocupan el mismo espacio que los referentes literarios de antaño. Lo alto y lo bajo, lo perdurable y lo efímero se confunden en una misma pasta compacta por las paletas móviles de su implacable máquina trituradora. Todo cabe en ella en virtud de una subversiva voluntad igualitaria. (Goytisolo 2010)

Ferré pretende, pues, que no se le escape ni un pixel de la cultura digitalizada ("las manifestaciones artísticas contemporáneas" antes mencionadas por Goytisolo). Su intención es claramente borrar las fronteras culturales con ánimo a veces provocador, para proponerle al lector un juego laberíntico de pistas referenciales, desde una perspectiva intertextual ampliada, digamos intersemiótica, tan característico de ciertas obras de la posmodernidad (pienso por ejemplo en la trilogía de Eduardo Mendoza, iniciada en 1978 con El misterio de la cripta embrujada). Pero también dar cuenta de una mutación cultural perceptible en la evolución de la estética realista, que ha dominado hasta hoy bajo diferentes formas (desde el realismo decimonónico hasta el realismo generalizado pasando por el realismo social), hacia lo que Ferré llama un "realismo de alta definición" y que define de este modo:

Cuando se ha consumado la digitalización de la realidad, es decir, el proceso de desrealización por el que la realidad se sitúa por entero bajo el signo y el imperio de lo virtual, ¿qué otra opción le queda a la narrativa, en este contexto de máxima inestabilidad de los referentes, excepto la de hacerse tan mediática y tecnológica como la realidad? Así, y solo así, podría hablarse de un realismo de alta definición, esto es, un realismo que tome plena conciencia del creciente dominio de lo artificial sobre todos los ámbitos de la realidad. (Ferré 2006: 11)

Entendemos que el realismo de alta definición es totalmente paradójico en sí, ya que se define como estética de lo artificial, o más bien estética de la realidad artificial. En Providence, el "dominio de lo artificial" se manifiesta a través de la imagen virtual, en particular del $\operatorname{cine}^{5}$ y del videojuego; dejaré de lado el cine, aunque sea provisionalmente, para concentrarme en el videojuego porque Providence se presenta ante todo como un videojuego experimental. Fiel a su concepción "libertaria" de la cultura, Ferré elige un soporte "ilegítimo" desde el

\footnotetext{
${ }^{5}$ El primer paradigma cultural de la novela no es el videojuego sino el cine, y las referencias al séptimo arte merecen en sí un análisis sobre el que no podemos ocuparnos en este artículo. La primera de ellas, la encierra el título de la novela, Providence, que remite a Howard P. Lovecraft como aprendemos nada más abrirla, pero también a la película homónima de Alain Resnais, aludida en el texto en dos ocasiones. En la primera parte, donde Álex le confiesa al productor francés Gaspard Guimard odiar el cine de Resnais (2009: 37); en la segunda parte, en un momento en que Álex consigna su profundo tedio tras sus primeros días en Providence: "Providence es Providence. Vade retro Alain Resnais" (2009: 151). Esas referencias pueden ser intertextuales (y adoptar diferentes formas: referencias o alusiones a películas, directores, actores, mise en abîme de películas, uso de un vocabulario técnico cinematográfico en la narración, etc.), pero también formales, ya que la gran mayoría de los capítulos del texto son "tomas" e "insertos" (en total, veintiocho tomas y diecinueve insertos).
} 
punto de vista de la cultura dominante, y a la vez muy representativo de la (sub) cultura de masas y por ende, del sistema capitalista de la cultura que la sostiene (Jameson 1991: 16), denunciado por Ferré (2006: 231). También lo elige por su carácter eminentemente "simulacral". La calidad de un videojuego, según sus usuarios, estriba en dos cosas: el grado de "realismo" y la relación entre la libertad del jugador y el respeto de las reglas del juego, lo que se denomina gameplay. En relación a su dimensión realista, el videojuego no se propone imitar la realidad, basándose simplemente en una estética mimética, sino que pretende imitar (mimesis) la representación que tenemos de la realidad (simulacro), a través de la fotografía, del cine, etc. (Jullier 1998: 82) ${ }^{6}$.

Bajo esta perspectiva, Ferré trata de observar los efectos de la revolución digital a principios del siglo xxl, y se pregunta en qué medida la "realidad virtual" es una amenaza para la realidad "real", si entendemos la realidad virtual como una experiencia "multimediática e interactiva" (Diodato 2011: 16) ${ }^{7}$, con la que se pretende crear la "ilusión", y no una simple reproducción, de la realidad (2011: 36). En este contexto, el videojuego se convierte en paradigma estético del "realismo de alta definición", así como del funcionamiento de nuestra sociedad "espectacular" (Debord 1967 1988), capitalista, consumista y, según el escritor malagueño, falsamente democrática.

\section{Un Videojuego llamado Providence(s)}

¿En qué consiste Providence? Y, primero, ¿de dónde viene este nombre? El origen de Providence es bastante misterioso y su génesis presentado como si de un enigma se tratase. Al principio, Providence o Providenz-cuya zeta final recuerda el nombre del célebre videojuego Civilization, que fue uno de los primeros videojuegos de estrategia ${ }^{8}$, pero también al film eXistenZ de David Cronenberg ${ }^{9}$, es el título de un proyecto de documental ruso inacabado, interrumpido por la muerte inesperada de sus dos autores, Alentova y Volkov (Ferré 2009: 9-33). Y para Álex, Providence no es más que el nombre de un encargo: en Cannes, después del fracasado estreno de su película en el Festival, una tal Delphine le pide

\footnotetext{
6 "Les concepteurs d'images de synthèse photoréalistes cherchent moins à imiter le monde que les photographies du monde. On assiste ainsi dans beaucoup de productions 3D à toutes sortes de tentatives pour renvoyer aux arts de l'empreinte [...]. A. Buttard [...] se demande si nous allons vers un néopicturalisme numérique, à l'image des photographes pictorialistes de 1890-1910 qui singeaient les attributs du tableau peint pour faire accéder leur pratique au statut d'art". ("A los conceptores de imágenes sintéticas fotorrealistas les interesa menos imitar el mundo que las fotografías del mundo. Así que en muchas producciones 3D, se encuentran muchas tentativas para referir a las artes de la huella [...]. A. Buttard se pregunta si vamos hacia un neopicturalismo digital, recordando a los fotógrafos pictorialistas de los años 1890-1910 que imitaban servilmente las técnicas de la pintura para alzar su práctica a nivel de arte" [La traducción es mía]).

7 La traducción es mía.

8 Civilization es un videojuego en que el usuario debe recrear una civilización entera, desde la Edad del Hierro hasta la carrera espacial.

${ }^{9}$ En eXistenZ la inmersión en el espacio digital se produce a través de la conexión directa de la consola (la vaina génica) con el sistema nervioso, y, como en Matrix, se genera el entorno de realidad virtual en la mente del usuario.
} 
que escriba un guión basado en el proyecto de los dos cineastas rusos, y le propone hacerlo desde la ciudad de Providence, en los EE.UU. Álex descubre posteriormente que el documental se basa en la novela de Arkady (mezcla de "arcade"10 y Atari) Rubliov (¿trasunto de Isaac Asimov?), también ruso, titulada Cristal líquido, en la que se narra la historia de un joven inventor que crea un programa informático que lo mata, absorbiendo su cerebro (94-107). Además, averigua que del documental se ha creado un videojuego experimental peligroso, todavía en circulación (82-94): "un videojuego experimental concebido con la finalidad de poner a prueba la adaptación de los seres humanos a las reglas cada vez más competitivas del sistema económico" (107).

Providence es así un producto del sistema capitalista: es un juego de estrategia que consiste en eliminar la secta rival de la Hermandad de los Amigos del Crimen Perfecto, la Iglesia Escarlata, para apoderarse del control de la ciudad. Ahora bien, la secta de la Hermandad tiene como dios el Mercado, como muestra su profesión de fe (485-490), y considera que "[toda la] energía encerrada en el cuerpo de los individuos [una energía sexual, se entiende] debe ser extraída de algún modo para reinvertirla en el funcionamiento de la maquinaria tecnológica y económica del capital" (543), mientras que la Iglesia aboga por la mera liberación de esa energía sexual... Para llegar a ese fin, Álex tiene que acostarse con el mayor número posible de mujeres, es decir consumir sexo y pornografía.

Pero Providence es también el nombre oculto de un "pacto entre caballeros" (57-70) firmado por Álex y Mohamed Abdullah Al-Razed. En realidad, un pacto faustiano, en el que se le propone a Álex "cambiar de vida" y "tener éxito de verdad" (63), sin que sepa cuál es el precio a pagar. Al presentarle las ventajas del "experimento", el misterioso Al-Razed le dice a Álex que:

Se le ofrecerán oportunidades exclusivas, le harán propuestas que no podrá rechazar, su vida, incluso las partes más satisfactorias de la misma, mejorarán de manera notable. [...] Será su vida, pero será mucho más que su vida. Una vida más plena, si quiere, mucho más satisfactoria en todo. [...] Habrá entrado en otra dimensión sin darse cuenta siquiera de haber abandonado una anterior. (Ferré 2009: 69)

Providence es, pues, un videojuego a escala humana, en el que se confunden los niveles de "realidad", por lo que deja de ser un juego, incluso un juego de rol, ya que de un juego se puede salir cuando se quiere (Caillois 1958, 1967), mientras que de Providence no se puede salir: no existe frontera entre el juego y el no juego, siendo la realidad virtual un espacio "donde la frontera se vuelve territorio", como bien dice el filósofo Roberto Diodato (2011: 27). Y en efecto, después del trato, Álex no sabe con certidumbre si ha soñado o no:

Realmente no sé si yo también me quedé dormido entonces sin darme cuenta, y todo lo que sucedió después es producto de un sueño acunado por el ruido

\footnotetext{
${ }^{10}$ Arcade se refiere en inglés a las salas de videojuegos (arcade amusement, video arcade) y al videojuego Arcade Game.
} 
de los motores de la piscina, o si mis recuerdos corresponden o no con exactitud a mis vivencias, o han sido fantaseadas por el olvido y la imaginación. No es fácil establecer la diferencia entre todos estos regímenes de la percepción. Las razones por las que pienso que pudo ser un sueño, contra todos los indicios materiales, son obvias. Pero todo sucedió de modo tan real que es imposible resistirse a la idea de que me sucedió en este nivel de la conciencia, donde la experiencia objetiva y la subjetiva se confunden... (Ferré 2009: 56-57)

En este nivel de realidad, donde se confunden conciencia e inconsciencia, lo virtual se ha impuesto a lo real. América no es sino una "plataforma espectral" y la ciudad de Providence es "uno de sus portales más transitados" (547). De hecho, el lema del videojuego es "Esto no es un juego. Es la realidad" (82).

Al final del juego, Álex es conducido al búnker, llamado HD-Rainbow (doble homenaje a la tecnología de alta definición y a El arco iris de la gravedad, de Pynchon, sátira sobre la televisión comercial) de un tal "Darth el Deconstructor"; allí, se encuentra frente a un centenar de pantallas que emiten imágenes de Providence y sus alrededores. En este "nuevo orden mediático-militar" (537), la guerra que va a estallar entre las dos sectas, se convierte en un "espectáculo inaudito" donde las imágenes fomentan "la ilusión de que todo está bajo control y, sobre todo, hace[n] de esta ilusión un gran espectáculo consumible por las masas, que son las que fantasean con esta posibilidad para imponer límites a su conducta y a la de los demás" (545).

Providence es un instrumento no solo del capitalismo, sino también de un sistema totalitario cuyo objetivo es eliminar a los seres humanos: en la cuarta parte de la novela, se confirma que Álex ha sido manipulado desde el principio para formar parte de una "red neuronal artificial", capaz de crear "modelos y pautas de representación" (572) para "renovar por completo la realidad, de arriba abajo. Proporcionándole una apariencia de novedad, unos retoques drásticos de cirugía plástica" (577). El objetivo de esta sustitución es por fin revelado: obtener la inmortalidad (573), es decir, conferirle al ser humano lo único que no puede poseer con dinero, o sea, tiempo, la vida eterna. A los usuarios se les promete la eternidad en el mundo virtual, a cambio de su muerte en el mundo analógico, real.

El nombre de Providence remite, por tanto, al documental, al videojuego, a la ciudad norteamericana que le sirve de escenario y a su ciudadano de honor, H. P. Lovecraft -recordemos que la palabra "providence" aparece en el epitafio de su tumba-. Pero también, aunque de manera más críptica, al cine de la Nouvelle Vague -Providence es el título de una película de Alain Resnais, ganadora del Festival de Cannes en 1978-, y a la filosofía del Marqués de Sade-Providence es el título de uno de sus libelos-, de la que Ferré es un gran conocedor ${ }^{11}$. Y finalmente, también remite a la religión cristiana, donde 'providencia' es sinónimo de la protección (por anticipación) de Dios o incluso de Dios mismo. Si nos fijamos en este último sentido, vamos a ver que Providence resulta ser un nombre bastante irónico, pero volveremos sobre este aspecto más adelante... El nombre de Provi-

\footnotetext{
11 Planeamos dedicarle un estudio específico a este aspecto en un trabajo posterior en la medida en que es una constante en la narrativa de Ferré que va más allá del caso singular de Providence.
} 
dence funciona como unas cajas chinas o, más bien, como una serie infinita de pantallas. Y conforme avanza el relato, Álex descubre que detrás de lo que creía que era Providence, aparece otra Providence, de manera que Providence es un simulacro potencialmente infinito. Cuando al final de la tercera parte, Álex cree haber descubierto por fin lo que es Providence, le dicen: "Cómo puede ser tan ingenuo. Providence es solo un espejo engañoso de otra realidad. Un programa simulado. Una versión autónoma de un supuesto programa inicial" (562). Providence es, pues, un simulacro de simulacro: es el simulacro por antonomasia, se trata de una copia que implica la destrucción del original, y su deformación al ser copiado. Como explica Baudrillard:

Tal es la simulación, oponiéndose a la representación. Ésta toma como punto de partida el principio de equivalencia entre el signo y la realidad (aunque esta equivalencia resulta utópica, es un axioma fundamental). La simulación, al contrario, parte de la utopía del principio de equivalencia, parte de la negación radical del signo como valor, parte del signo como revés y condena a muerte de cualquier referencia. Mientras que la representación intenta absorber la simulación interpretándola como representación falsa, la simulación envuelve todo el edificio de la representación como simulacro ${ }^{12}$. (Baudrillard 1981: 16)

Providence tiene sus reglas como cualquier juego, aunque Al-Razed permanece bastante evasivo al respecto; solo avisa a Álex de que "su obra será la [suya]" y de que "tiene tiempo por delante" antes de que le comuniquen que "ha llegado la hora", que tiene que "pagar su deuda" (Ferré 2009: 69). Es una pareja de misteriosos detectives quienes avisan a Álex de las verdaderas reglas, y de que el juego produce un efecto de adicción que puede ser mortal -véase el "inserto 2" (107)-. En realidad, el juego funciona como un snuffmovie, es decir, al final se elimina al jugador absorbiéndole los sesos, como en la novela de Rubliov. En este sentido, el nombre de Providence es más bien irónico, a no ser que garantice, no la protección del jugador, sino más bien del que lo ha concebido...

Para Álex, la dificultad estriba en que desde el principio no es capaz de entender que ha entrado en el videojuego y que lo virtual se está imponiendo a lo real, pese a las advertencias que recibe y pese a ser "un profesional de la imagen". Su ceguera simbólica le lleva a vivir experiencias traumáticas muy violentas, alejándose cada vez más del éxito prometido, y aproximándose cada vez más al caos. Así, salvo un breve periodo feliz donde acumula las experiencias sexuales más diversas (con adolescentes, estudiantes, colegas de trabajo, mujer policía, etc.), no deja de ser violentado según un esquema repetitivo, y a la vez in crescendo, que recuerda la estructura Die\&Retry (literalmente "muere e inténtalo de nuevo") del

\footnotetext{
12 "Telle est la simulation, en ce qu'elle s'oppose à la représentation. Celle-ci part du principe d'équivalence du signe et du réel (même si cette équivalence est utopique, c'est un axiome fondamental). La simulation part à l'inverse de l'utopie du principe d'équivalence, part de la négation radicale du signe comme valeur, part du signe comme réversion et mise à mort de toute référence. Alors que la représentation tente d'absorber la simulation en l'interprétant comme fausse représentation, la simulation enveloppe tout l'édifice de la représentation lui-même comme simulacre" [La traducción es mía].
} 
videojuego: es atacado y/o torturado (es incluso violado) por varios individuos o grupos de individuos que lo dan por muerto (129-136, 237, 450-458, 490, 532).

En este sentido, es interesante volver sobre el nombre y el contenido del juego. Al-Razed le propone a Álex "tener", tenerlo todo en realidad, lo que sugiere una de las grafías del juego, "Providens" con "s" (94): una mezcla entre el adjetivo verbal latino en "ens", cuyo equivalente castellano sería el gerundio, y el verbo inglés "to provide", que significa suministrar. Providence es el juego que te lo suministra todo, incluso la eternidad en la muerte, en un espectáculo 3D, una especie de condensado caricaturesco de la sociedad de consumo: "¿no querría ver el Apocalipsis en directo por televisión, con el arco iris multicolor como remate final a lo Canal Disney?" (559), le preguntan a Álex, al final del juego...

Providence sería, pues, una metáfora de la sociedad del capitalismo tardío, fundada en una asociación letal entre capitalismo y tecnología. No puede ofrecerse visión más negativa de la imagen virtual como metáfora de la opresión del individuo por el sistema capitalista... A principios de los años 80, Baudrillard ya asimilaba los EE.UU. a un gran parque temático tipo Disneyland, cuyo ideal democrático había sido pervertido por el sistema capitalista (1981: 25-26) ${ }^{13}$. Veinte años antes de la revolución digital y la aparición de Internet en nuestras vidas, el filósofo francés ya señalaba que el desarrollo de las tecnologías de la comunicación y la información, estaba provocando la sustitución de la realidad por los "signos" de la realidad, la sustitución de la realidad por "el principio de realidad" (1981: 11-12), condenando a muerte nuestra civilización.

Pero la dominación progresiva de Álex por el juego, como metonimia de la superación de lo real por lo virtual, ese proceso de "desrealización psíquica y material" que hace "vacilar nuestras convicciones más arraigadas" subrayado por Ferré (2006: 238) y antes de él por Jameson (1991: 46) y, de nuevo, Baudrillard (1995: 47), se manifiesta a través de varios elementos textuales que me gustaría comentar a continuación.

\footnotetext{
13 "Disneyland est là pour cacher que c'est le pays 'réel', toute l'Amérique 'réelle' qui est Disneyland (un peu comme les prisons sont là pour cacher que c'est le social tout entier, dans son omniprésence banale qui est carcéral). Disneyland est posé comme imaginaire afin de faire croire que le reste est réel, alors que tout Los Angeles et l'Amérique qui l'entoure ne sont déjà plus réels, mais de l'ordre de l'hyperréel et de la simulation. II ne s'agit plus d'une représentation fausse de la réalité (l'idéologie), il s'agit de cacher que le réel n'est plus le réel, et donc de sauver le principe de réalité. L'imaginaire de Disneyland n'est ni vrai, ni faux, c'est une machine de dissuasion mise en scène pour régénérer en contre-champ la fiction du réel [...]. Ce monde [Disneyland] se veut enfantin pour faire croire que les adultes sont ailleurs, dans le monde 'réel', et pour cacher que la véritable infantilité est partout, et c'est celle des adultes eux-mêmes qui viennent jouer ici à l'enfant pour faire illusion sur leur infantilité réelle" (1981: 25-26). ("Disneyland está presente para ocultar que todo el país real, todos los EE.UU. reales son Disneyland (un poco como las cárceles están presentes para ocultar que lo social en su conjunto, en su omnipresencia tétrica, es carcelario). Se plantea Disneyland para que creamos que el resto es real, cuando todo Los Ángeles y los EE.UU. que la rodean ya han dejado de ser reales, para ser hiperreales y simulacrales. Ya no se trata de una falsa representación de la realidad (la ideología), se trata de ocultar que lo real ya no es lo real, y de salvar pues, el principio de realidad. El mundo imaginario de Disneyland no es real, tampoco es falso, es una máquina disuasoria puesta en escena para regenerar en contrapicado la ficción de lo real [...]. Este mundo pretende ser infantil para hacernos creer que los adultos están por otro lado, en el mundo 'real', y para esconder que la verdadera infantilidad está por todas partes, y es la de los propios adultos que vienen allí para hacer de niños y engañarse sobre su propia infantilidad" [La traducción es mía]).
} 
2. El proceso de "desrealizacion psíquica y material" de Álex

\title{
2.1. ADICCIÓN
}

Álex muestra una incapacidad cada vez mayor por controlarse debido al consumo de droga. En casa de los Klingon, le suministran Blue moon:

\begin{abstract}
[Una] droga de alta definición. No provoca alucinaciones, no te sumerge en ninguna realidad que no sea la que tienes frente a los ojos. Eso sí, te hace percibir sus texturas y volúmenes con una nitidez casi digital. Cuando se pasa el efecto, la realidad te parece insulsa, plana. Bienvenido a la realidad. Por eso hago cine. Es como esta droga poderosa, un transformador de niveles de realidad ${ }^{14}$. (Ferré 2009: 146)
\end{abstract}

La droga actúa como un videojuego adictivo en el que el jugador se vuelve incapaz de abandonar el partido. Su consumo crece a un ritmo cada vez más rápido, lo que provoca en Álex reacciones inesperadas: puede ser presa de arrebatos de violencia, como ocurre con la destrucción de los carteles de los Klingon (219), o víctima de alucinaciones, pese a lo que dice (véase supra). Por ejemplo, la manera en la que Álex vive la fiesta, en el edificio blanco del centro de la ciudad de Providence, y su posterior incendio, muestran que su visión está totalmente deformada: bajo la influencia del recuerdo de las imágenes televisivas del 11-S, y de la película de F. F. Coppola Apocalypse now, Álex, que va disfrazado de bombero, simula el rescate de Eva (500-501). Es quizás el momento en que su impostura alcanza una especie de clímax, ilustrando su alienación -en sentido etimológico de ser "otro"-, así como la más perfecta ilustración de que la lógica de Providence es la del simulacro y la del plagio.

En realidad, la droga no es sino una manera redundante de significar la adicción de Álex, su condición adictiva: adicto a la droga, pero sobre todo a la imagen y a la realidad impostada difundida por las imágenes; la droga "de alta definición" es a su vez un sustituto metonímico, un simulacro de la realidad de alta definición, siendo la "alta definición" el concepto clave de la realidad virtual según Baudrillard:

El concepto clave de esta Virtualidad es la Alta Definición [...]. Por todas partes, la Alta Definición marca la transición, más allá de toda determinación natural, hacia una fórmula operacional -"definitiva" precisamente-, hacia un mundo donde la sustancia referencial se hace cada vez más escasa [...]. La imagen de alta definición. Nada que ver con la representación, menos aún con la ilusión estética. Toda la ilusión genérica de la imagen se halla aniquilada por la perfección técnica. Holograma o realidad virtual o imagen tridimensional, ya no es más que la manifestación del código digital que la genera. Ya no es sino la rabia de hacer que una imagen deje de ser una imagen, es decir justamente lo que le quita una dimensión al mundo real15. (Baudrillard 1995: 51)

\footnotetext{
${ }^{14}$ El subrayado es mío.

15 "Le concept clef de cette Virtualité c'est la Haute Définition [...]. Partout le Haute Définition
} 
La desrealización de la realidad a favor de lo virtual, la desaparición de la "sustancia referencial", encuentra su eco máximo en la evolución de la relación de los personajes de la novela con lo más concreto del ser humano, es decir, el cuerpo; se nota particularmente en el cuerpo a cuerpo de la relación íntima:

... en los últimos cinco años la mayoría de mis relaciones habían sido con actrices [...]; amoríos con imágenes en el cristal del espejo o la superficie de la pantalla, no con mujeres reales. Las deseaba como se desea una presencia en una película o una fotografía en un reportaje o incluso un desnudo en un cuadro. Pero siempre faltaba algo, una dimensión esencial, [...] todas esas imposturas creadas por el sistema para saciar la libido entumecida de los consumidores (comenzando por Keeley, mi sucedáneo favorito), no eran [reales] en absoluto. (Ferré 2009: 280)

Si llevamos la lógica del consumo de sexo hasta sus extremos, vemos que, además de estribar en una visión sexista y degradante de la mujer, conduce a una desmaterialización paradójica del cuerpo de esta: sexo con mujeres de carne y hueso que, a causa del poder de las imágenes, llega a convertirse en sexo virtual...

\subsection{UN ESPEJO ENGAÑOSO DE LA REALIDAD}

Del mismo modo, asistimos a la desintegración casi "material" de Álex al volvérsele extraño su propio reflejo. En efecto, la única imagen que no logra reconocer es la que le devuelve el espejo de su cuarto de baño: "frente al espejo del mueble de madera tallado por el macho artesano Klingon, veo mi cara iluminarse al sonreír con gesto luciferino. No soporto esa mirada mucho tiempo. No sé si me pertenece. Me da miedo. Esto no puede sino acabar mal" (Ferré 2009: 144-145) y un poco más adelante: "Antes de acostarme, me sucede algo insólito, demencial. Veo un rostro en el espejo que me aterroriza. No es el mío. Me quedo fascinado mirando mi nuevo rostro, observándolo fijamente, como si no supiera quién era, o me negara a reconocerlo. Es la cara de Mohamed Atta, o de un doble perfecto de Atta, nunca se sabe" (157). Parece sucederle a Álex lo mismo que a Dorian Gray en la novela de Oscar Wilde, como si Álex le hubiera vendido su alma / su cuerpo al diablo... El reflejo de la realidad en el espejo no implica a la tecnología digital, contrariamente a lo que ocurre con el videojuego, pero la imagen que se refleja en el espejo, sí: es una imagen mediática, de origen televisivo (Mohamed Atta es uno de los terroristas implicados en los atentados del 11 de septiembre); como escribe Ferré en Mimesis y simulacro: "toda experiencia realista es en esencia una experiencia fantástica [...]. El territorio más fantástico que quepa concebir:

\footnotetext{
marque le passage, au-delà de toute détermination naturelle, vers une formule opérationnelle -'définitive'précisément -, vers un monde ou la substance référentielle se fait de plus en plus rare [...]. L'image de haute définition. Rien à voir avec la représentation, encore moins avec l'illusion esthétique. Toute l'illusion générique de l'image est anéantie par la perfection technique. Hologramme ou réalité virtuelle ou image tridimensionnelle, elle n'est plus que l'émanation du code digital qui la génère. Elle n'est plus que la rage de faire qu'une image ne soit plus une image, c'està-dire justement ce qui ôte une dimension au monde réel" [La traducción es mía].
} 
el páramo digitalizado de lo real" (2006: 236). A partir de allí, Álex no deja de vivir momentos de suplantación/desdoblamiento de personalidad, donde se confunde con cineastas famosos a los que dice a modo de despedida: "Vade retro, XX". En total unas trece despedidas a Satanás disfrazado de cineasta: Woody Allen, Alain Resnais, Sam Peckinpah, etc ${ }^{16}$. Progresivamente, Álex pierde su identidad y no ve la realidad sino a través de otros, su percepción de la realidad ya no le pertenece totalmente.

\section{De LA ESPECULARIDAD A LA CEgUera}

\section{1. Del Videojuego al CINE y VICEVERSA}

En Providence, el enemigo de Álex no es la Iglesia escarlata, ni siquiera Andy Ross, su violador, sino la imagen, una imagen que no deja de reproducirse, y acaba por cegarlo. Como en la ciudad, todo el relato funciona sobre el principio de la mise en abîme, que le confiere al texto una dimensión especular paradójica, ya que no favorece la identificación sino que, muy al contrario, produce una diseminación del sentido (Baudrillard 1981: 123-124). Ha llegado el momento de interrogarse de nuevo sobre el soporte subcultural que sostiene el edificio novelesco de Providence. En realidad, no se trata tanto del videojuego, como de la imagen del videojuego transmitida por el cine. Al principio de esta reflexión, he mencionado la película de Cronenberg, eXistenZ, como referencia posible del nombre Providenz. La película cuenta la inmersión de dos individuos en el mundo virtual de un videojuego gracias a una red alámbrica a la que se conectan desde su cama. Ahora bien, como subraya Alexis Blanchet, no se trata de un simple "juego", y en este sentido se parece mucho a la novela de Ferré, porque "los jugadores de eXistenZ están como atrapados por el juego en una especie de confusión e indiferenciación entre su vida real y la experiencia lúdica" (2012: 82)17. Del mismo modo, la escena final donde Álex está conectado con el ordenador de Darth recuerda Johnny Mnemonic (Robert Longo) o Nirvana (Gabriele Salvatores), ambas películas inspiradas en Quemando cromo, una recopilación de cuentos de William Gibson que incluye el famoso "Neuromante", y una de las referencias literarias de Ferré. No se trata de hacer aquí un recuento de todas las películas sobre videojuegos que han podido inspirar a Ferré: ya que, además de inútil, resultaría imposible. Pero vemos que dejar de lado el cine, no es sino provisional. Como conjetura, uno de los personajes de Providence nos dice que:

En lugar de que el cine se haya ido pareciendo cada vez más a la realidad, ha sucedido a la inversa y la realidad se ha ido pareciendo más y más al cine has-

\footnotetext{
16 "Providence es Providence. Vade retro Alain Resnais" (Ferré 2009: 151); "Vade retro, Larry King" (172); "Vade retro, Steven Spielberg" (177); "Vade retro, Michael Powell" (182); "Vade retro, Bernardo Betolucci" (185); "Vade retro, Joseph Losey"(196); "Vade retro, Dziga Vertov" (204); "Vade retro, Leni Riefensthal. Vade retro, Spike Lee" (209); "Vade retro, Douglas Sirk" (215); "Vade retro, Woody Allen" (224); "Vade retro, Stanley Kubrick" (252); "Vade retro, Sam Peckinpah" (463).

17 "Les joueurs d'eXistenZ sont comme happés par le jeu dans une forme de confusion et d'indifférenciation entre leur vie réelle et l'expérience 'ludique'"' [La traducción es mía].
} 
ta el punto de hacerse indistinguibles [...] si la vida se ha vuelto similar a una película, qué les queda a las películas por hacer. ¿Parecerse a un videojuego? (Ferré 2009: 119)

Y en efecto, los vaivenes entre cine y videojuego son constantes desde la aparición de los videojuegos en los años 70. No es este lugar para una reflexión sobre las relaciones entre esas dos formas de "arte" (el séptimo y el... ¿décimo?), pero es interesante analizar la función de esta mise en abîme de la imagen del videojuego en la imagen cinematográfica: es una manifestación particularmente original de la cultura del remix, donde Ferré recurre a la representación (mimesis) de un soporte subcultural "simulacral" (el videojuego), por otro soporte subcultural "simulacral" (el cine de videojuego), sabiendo que los videojuegos se inspiran a su vez a menudo en subgéneros cinematográficos como el cine de ciencia ficción, el cine de aventuras, etc. (Blanchet 2012: 125); más allá del resultado, es interesante subrayar la sistematización del proceso de mixing, bajo una forma centrípeta en cierto sentido, como rasgo característico de la estética de la mímesis "simulacral".

\subsection{DiseminACIÓN DEL SENTIDO}

Las huellas de la mise en abîme están por todas partes. De manera bastante significativa, Álex, cineasta, no deja de filmar cuanto lo rodea (sus amantes en particular, pero también la casa donde se hospeda, las ardillas del parque alrededor de la casa o una fiesta en casa de estudiantes mexicanos, etc., a lo American Beauty) y, cuando no graba, contempla la realidad con la mirada de un director de cine: "Eva se deslizó por mi lado a cámara lenta y me tendió la mano fotograma a fotograma para invitarme a acompañarla..." (Ferré 2009: 294); "Pude ver entonces, en un inserto ralentizado..." (302). Está tan obsesionado por la imagen que la ve incluso donde no está; así es como, en varias ocasiones, está convencido de que lo están filmando $(20,28,172,275)$, u, otras veces, la ausencia de la cámara digital le afecta profundamente, como cuando está con Eva en la isla de Martha's Vineyard: "Alguien debería habernos inmortalizado entonces, con una instantánea o una cámara de vídeo de baja definición, alguna constatación visual de que eso existió, de que algo especial sucedió entre nosotros durante la travesía marítima hacia la casa de la playa" (274). Esta omnipresencia de la imagen dentro de la imagen, bajo todas sus formas, no le da a Álex un horizonte demultiplicado, sino más bien al contrario: lo encierra cada vez más en un mundo virtual. Este encierro lo simboliza un objeto concreto y aparentemente anodino, como son las gafas de sol. Al final de la tercera parte, Álex confiesa echar de menos sus gafas de sol, sin que parezca venir a cuento (505 y 506); y, una vez en el búnker de Darth, tiene que llevar sus gafas de sol antes de sucumbir al "bombardeo mortal de imágenes": "Póngase las gafas de una vez, reclínese en el asiento y deje ya de gimotear, maldito latino quejica. Ha empezado la descarga del programa y no está conectado aún el dispositivo inalámbrico" (559). Parecen un atuendo irónico en estos momentos, pero son otra pantalla más, otro intermedio entre él y la realidad, la 
realidad virtual/digital de las imágenes. Pero ese intermedio no funciona como un filtro, sino como una pantalla oscura, opaca, que solo provoca una interferencia, haciendo cada vez más difícil la visión y, por tanto, la interpretación de la realidad:

No veo nada / La ceguera es un estado normal al principio. No se impaciente. [...] Una descarga acelerada de imágenes aún más abstractas e indefinidas lo ciega en un primer momento, antes de que Álex pueda acostumbrarse otra vez a las condiciones de la visión. Un brillo intenso de tonalidad azul penetra por el borde lateral de las gafas, como una cuña o una astilla iridiscente, y luego vira al rojo y al verde con brusquedad, causándole agudas molestias en el ojo derecho, como incisiones microscópicas en el tejido nervioso, y perturbando de ese modo su capacidad inicial de concentrarse en el flujo de colores, gamas y texturas que inunda ahora sus doloridas retinas. (Ferré 2009: 561-562)

De hecho, Álex no llegará nunca a Providence: "Lástima, Franco, que no pueda verlo, como suele decirse, con sus propios ojos", le advierte Darth irónicamente (563).

\section{VIRTUALIDAD Y TOTALITARISMO}

\subsection{ABOLICIÓN DEL "Yo"}

Como ya hemos dicho, Providence es, entre otras cosas, un videojuego que pone a prueba la resistencia del individuo frente a un sistema capitalista cada vez más liberticida. Es una crítica de la ideología liberal en toda regla, una constante en la obra del escritor (véase su última novela, Karnaval, al respecto). La perdida de la autonomía de Álex, y su falta de resistencia al sistema, se manifiestan también a través de la narración. En la mayoría de los capítulos de la primera parte, se hace uso de la narración en primera persona: Álex es un narrador autodiegético, excepto en algunas ocasiones, en las que la narración pasa a una tercera persona (el relato del origen del juego por Delphine, la visita de los detectives, los insertos en bastardillas sobre las características "técnicas" del juego y el epílogo). En la segunda parte, pasa lo mismo o casi: Álex sigue siendo el narrador principal -sobre todo si se toma en cuenta el hecho de que las primeras páginas de esta parte corresponden a un diario íntimo que se extiende del lunes 4 al sábado 30 de septiembre (Ferré 2009: 139-252)-, pero se multiplican las ocasiones en que la narración pasa a una tercera persona: dos capítulos donde una voz anónima relata el guión de sendas películas/cortometrajes de Álex (284-286 y 366-369), seis capítulos que corresponden a e-mails de Jack Daniels enviados a Álex, un inserto donde está reproducido un artículo sacado de una guía turística de la ciudad de Providence (157-160), y el epílogo, también en tercera persona. En cambio, en la tercera parte, la narración se abre y se cierra con la tercera persona, y la primera solo reaparece en dos ocasiones: en primer lugar, durante la fiesta y el incendio de la torre blanca y en segundo lugar, durante el secuestro de Álex en casa de Vidart. En la cuarta parte, la narración está enteramente a cargo de una tercera persona que actúa como un narrador omnisciente. 
La suplantación progresiva de la primera persona por la tercera ilustra perfectamente la sumisión de Álex al mundo virtual. El "yo" lleva cada vez menos la voz cantante, a favor de un "él" anónimo y todopoderoso. Además, conforme avanza el relato, el punto de vista del yo parece carecer cada vez más de credibilidad, siendo el relato de sus experiencias cada vez más extravagantes (me refiero en particular al relato de la fiesta y al posterior incendio de la torre blanca que parecen ser el resultado de una alucinación provocada por la droga como indicamos previamente). De todos modos, el mero hecho de que la tercera persona aparezca en la primera parte, muestra la fragilidad del yo y de su sumisión, aunque inconsciente, a una instancia superior que lo controla todo, incluso la ilusión de autonomía.

\subsection{Manipulación de LA "OBRA"}

La estructura de la novela imita la de un videojuego. La primera parte de la novela, titulada "El principio Delphine" (juego de palabras: principio del fin) se parece a una "secuencia cinemática", en la que el usuario no puede interactuar todavía con el videojuego: Álex descubre en qué consiste su "falsa misión" (escribir un guión) y qué peligros encierra; en esta "secuencia", Álex es bastante pasivo, sexualmente incluso, como sugiere el hecho de que le hace el amor a una muñeca de plástico.

La transición de la secuencia cinemática al primer nivel del juego se hace mediante un epílogo titulado "Informe 1, PVD" que relata el violento episodio de la detención de Álex en el aeropuerto de Providence, al intentar penetrar en el territorio estadounidense sin visado: esta secuencia parece funcionar como una prueba iniciática antes de entrar en el juego. La segunda parte de la novela, titulada "El movimiento browniano", en referencia a una teoría física sobre el movimiento aleatorio de las partículas de gran tamaño en un medio fluido, debido al bombardeo permanente de estas por las moléculas del líquido, corresponde, pues, al primer nivel del videojuego: una vez en Providence, Álex cambia efectivamente de vida y descubre su éxito entre las mujeres, convertido en serial-fucker, si se me permite tal expresión, pero también descubre la violencia y reanuda rápidamente con el fracaso que siempre ha marcado su vida. Su trayectoria vital sigue un movimiento aleatorio, favorecido por el consumo de droga, donde las imágenes desempeñan el papel de las anteriormente mencionadas moléculas de líquido.

El paso del nivel 1 al nivel 2 del videojuego se hace mediante un segundo epílogo, titulado "Informe 2, PVD", que se concluye con un mensaje electrónico encuadrado: "En caso afirmativo, clica sobre el icono 'CTHULHU'. En caso negativo, clica sobre el icono ' $P$ '. Si no pasas de pantalla, reinstala el programa inicial" (Ferré 2009: 409). Este mensaje parece dirigido a Álex, quien afirmaba unas páginas antes que iba a consultar su correo electrónico (386).

La tercera parte, titulada "Conspiración Cthulhu", parece indicar que Álex ha optado por clicar en la P, es decir que ha aceptado seguir jugando a Providence, bajo auspicios más que inquietantes como sugiere la vinculación con el uni- 
verso lovecraftiano: Cthulhu es en efecto el nombre de uno de los más famosos monstruos creados por el escritor norteamericano H. P. Lovecraft ${ }^{18}$, con cabeza de sepia, tentáculos y alas, y cuya característica es ser enemigo de cuanto existe...

Como ya hemos dicho, este nuevo nivel le resulta demasiado difícil a Álex: su misión es un verdadero fracaso y por tanto, es sacrificado.

La cuarta parte, titulada "Providence. Año uno", no corresponde a un "nivel" suplementario del juego, sino que constituye un epílogo donde las dos protagonistas femeninas del videojuego (Delphine y Eva) comentan la -pésima y triste, según ellas- participación de Álex en el experimento de Providence, y la próxima publicación de una nueva versión mejorada del videojuego (577), algo que ya había sugerido Darth (563). Esta parte parece corresponder más o menos a un bonus-track del videojuego, como una especie de anuncio publicitario destinado a promover el futuro producto.

De hecho, cabe subrayar que la novela, de casi seiscientas páginas, se compone dentro de cada nivel de una gran cantidad de capítulos -llamados "tomas" o "insertos", como si de un guión se tratase: ¿el guión de Álex, recuperado por Al-Razed?-, numerados de manera aparentemente aleatoria en eco al movimiento browniano... Un conjunto de veintiocho "tomas", numeradas de 1 a 99 y en la cuarta parte un conjunto de treinta fragmentos numerados de 3 a 142. La fragmentación y numeración del texto sugiere numerosas elipsis, a no ser que se trate de otra forma de manipulación del texto por parte del narrador: puede que haya hecho desaparecer fragmentos del mismo o que nos haga creer que los ha hecho desaparecer... Es imposible saberlo, pero el texto resulta "agujereado". Además, cabe destacar la presencia del capítulo titulado "Inserto 19. Exégesis", que se presenta como tres posibles desenlaces para la historia de Álex, tres finales que, según el narrador, "el infatuado Álex nunca contó" (526).

En este sentido, vemos que Ferré desarrolla hasta sus últimas consecuencias las estrategias de control del texto, así como de camuflaje de la instancia narrativa, en un último simulacro formal; una instancia narradora indeterminada pero dotada de un gran poder, que le permite decidir al final, como en una atracción de feria, "Ahora, todos abajo" (587). Los lectores, como los personajes, parecemos meras fichas en el juego/tío vivo letal de este narrador demiúrgico/ diabólico.

Según Ferré, en el sistema actualmente dominante, es decir el sistema capitalista, la realidad se está convirtiendo en un videojuego mortal. No se trata de una reflexión más sobre el poder de la imagen, sino más bien de una reflexión sobre lo que de este poder se hace; la realidad digital, virtual, debería existir como medio y no como fin; y, como tal, cabe pensarla de nuevo como factor de desarrollo de la democracia y no como soporte de un sistema que funciona como cualquier totalitarismo: triturando al individuo y negando su libertad.

Ahora bien, la suplantación de lo real por lo virtual cobra sobre todo un aspecto irónico, por no decir humorístico. Por ejemplo, el nombre y apodo de "Darth, el Deconstructor", antes mencionado, es un doble guiño paródico a Star

\footnotetext{
${ }^{18}$ Aparece en "The Call of Cthulhu", en su Anthology of weird tales (1928).
} 
Wars, como ya hemos dicho, pero también a la "French Theory", que encierra probablemente una crítica hacia la teoría de la deconstrucción vista como una impostura / un simulacro comparable al de "Darth Vader" en la película de Lucas... Pero más allá de sus referencias, que son incontables, destaca su crítica de la imagen: no se centra en la imagen en sí, sino más bien en su uso político, como instrumento de consolidación del capitalismo; lo que denuncia Ferré es la imagen espectacular en el sentido de Debord o de Jameson, es decir, como modo de promoción de la Mercancía y, por lo tanto, factor de reproducción del sistema de la sociedad de consumo. De ahí que el final del juego corresponda a una serie de "macroespectáculos" (la fiesta en el edifico blanco, su posterior incendio, la puesta en escena televisiva de la guerra en Providence $y$, por fin, la fiesta de fin de año que se celebra en ausencia de Álex en la planta ciento cuarenta de una misteriosa torre...). Y por eso tiene tanta importancia el cine como expresión artística en la novela; a través de sus fracasos, Álex es también el garante de que existe una imagen cinematográfica artística y no comercial, mercantil...

Mimesis y simulacro son los dos términos del título del ensayo de Ferré y resumen bien su propuesta estética: su obra no pretende imitar la realidad sino el simulacro en que se ha convertido la realidad, para mejor entenderla. Dotado de un flujo verbal potentísimo, tan potente como "el flujo total" de las imágenes denunciado por Jameson (1991: 125), Ferré pretende que el lector conozca un éxtasis a la altura de la droga que toma Álex, el bluemoon, para un trip inaudito en los territorios de la nueva literatura.

\section{OBRAS CITADAS}

Azancot, Nuria (2007): "La generación Nocilla y el afterpop piden paso". En: El mundo. El cultural, 19 de julio. Disponible en <http://www.elcultural.es/version_papel/ LETRAS/21006/La_generacion_Nocilla_y_el_afterpop_piden_paso/>. Última visita: 11.01.2010.

Baudrillard, Jean (1981): Simulacres et simulation. París, Galilée. (1995): Le crime parfait. París, Galilée.

Blanchet, Alexis (2012): Les jeux vidéo au cinéma. París, Armand Colin.

Borrá Castanyer, Laura (2005): Textualidades electrónicas: nuevos escenarios para la literatura. Barcelona, UOC.

Brea, José Luis (2007): Cultura_Ram. Mutaciones de la cultura en la era de la distribución electrónica. Barcelona, Gedisa.

Caillois, Roger $(1958,1967)$ : Les jeux et les hommes. París, Gallimard.

Debord, Guy (1967, 1992): La société du spectacle. París, Gallimard. (1988): Commentaires sur La société de consommation. París, Gallimard.

De Certeau, Michel (1974): La culture au pluriel. París, UGE.

Diodato, Roberto (2011): Esthétique du virtuel. París, Vrin.

Fernández Porta, Eloy (2010): Afterpop: la literatura de la implosión mediática. Madrid, Anagrama.

Ferré, Juan Francisco (2009): Providence. Madrid, Anagrama. (2011): Mímesis y simulacro. Ensayos sobre la realidad (del Marqués de Sade a David 
Foster Wallace). Málaga, e.d.a. libros.

Garandel, Pascal (2011): "Malaise dans Civilization". En: Rufat, Samuel y Ter Missinian, Hovig (eds.): Les jeux vidéo comme objet de recherche. París, Questions théoriques, pp. 124-145.

Goytisolo, Juan (2010): "Literatura en el ciberespacio". En: El País. Babelia, 1 de febrero. Disponible en <http://elpais.com/diario/2010/01/02/babelia/1262394740_850215. htm>I. Última visita: 15.08.2012.

Jullier, Laurent (1998): Les images de synthèse. París, Nathan Université.

Jameson, Fredric (1991): Le postmodernisme ou la logique culturelle du capitalisme tardif. París, Beaux-Arts de Paris éditions.

Pourriol, Ollivier (2008): Cinéphilo. Les plus belles questions de la philosophie sur grand écran, París, Hachette Littératures.

Rufat, Samuel y Ter Missinian, Hovig (eds.) (2011): Les jeux vidéo comme objet de recherche. París, Questions théoriques.

Triclot, Mathieu (2012): Philosophie des jeux vidéo. París, La Découverte. 